\title{
Retinoblastoma cM1 TNM Finding v7
}

National Cancer Institute

\section{Source}

National Cancer Institute. Retinoblastoma CM1 TNM Finding v7. NCI Thesaurus. Code C88777.

Retinoblastoma with systemic metastasis. (from AJCC 7th Ed.) 